\title{
Dyslexia and Enhanced Visuospatial Ability: A Maltese Study
}

\author{
Victor Martinelli \\ Faculty of Education, University of Malta \\ Deidre Fenech \\ Specific Learning Difficulties Unit, \\ Ministry for Education and Employment, Malta
}

\section{Doi:10.5901/ajis.2017.v6n1p103}

\section{Abstract}

The aim of this study was to explore the issue of adolescent learners with dyslexia and their visuospatial ability. There is a substantial body of findings in educational and psychological literature suggesting that individuals with dyslexia are likely to have high levels of visuospatial ability. A group of 38 thirteen-year-old male and female bilingual (Maltese and English) students who were ethnically Maltese and clinically registered as having dyslexia, participated in this study. They were recruited from secondary schools from a number of regions on the island of Malta and were considered to be representative of the wider population of similarly affected peers of their age. The research group was matched for age, sex, ethnicity and ability with another group of 38 peers who were average readers in English and who came from the same classes as the research group. Both groups completed a Maltese standardised English reading comprehension test to confirm their status as weak and competent readers respectively. They then completed a published paper-and-pencil test of visuospatial reasoning and an interactive, computer-based virtual reality test based on a similar test described in published literature (Bungalow Test). In general, males tended to outperform females but this was only statistically significant in one of the many measures they completed. No consistent and statistically significant differences were evident between the groups on the wide array of visuospatial measures administered. The findings suggest that in the groups studied, adolescent learners with dyslexia possessed similar visuospatial skills as their average peers.

Keywords: dyslexia, visuospatial ability, literacy, Maltese, bungalow test.

\section{Introduction}

Dyslexia is a prevalent form of reading disorder that may lead to "disengagement with the educational system ... behavioural problems, social exclusion and crime and reduced employment prospects (which in turn make mental illhealth more likely)" (Beddington et al., 2008, p. 1060). It is manifested in all languages including those with a nonalphabetic character system such as Chinese and Japanese (Sun, Lee, \& Kirby, 2010). Dyslexia is estimated to affect up to ten percent of the population of the United States of America (Siegel, 2006) and Australia (Vidyasagar \& Pammer, 2009). In the United Kingdom, Peterson and Pennington (2012) quote a percentage of seven percent. On the contrary, only about three percent of the Italian population of school-age children are estimated to have dyslexia (Barbiero et al., 2012). Given that bilingualism characterises Malta's linguistic reality (English and Maltese), the prevalence of dyslexia is likely to lie somewhere between that of Latin and the English speaking worlds. Research also shows that dyslexia is two or three times more prevalent in males than in females (Rutter et al., 2004) and represents the most prevalent type of learning difficulty among individuals with a learning disability (Lyon, 2003).

Students with weak literacy skills tend to have lower academic self-esteem than typical learners do (Beddington et al., 2008; Elbaum \& Vaughn, 2001; Gerber, 2012; Scott, 2004). Fluent reading and good writing skills are considered important for academic achievement but students with dyslexia usually lack these skills (Scott, 2004). In addition to many other challenges that students face, increasing demands on the person's literacy skills can cause prolonged stress and 
anxiety (Beddington et al., 2008). There is a paucity of research about the social and occupational situation of adults with dyslexia (Gerber, 2012). In many North American studies, individuals with learning disabilities (dyslexia) demonstrate lower levels of self-determined behaviour than their peers without disabilities and this has implications for academic achievement (Zheng, Gaumer Erickson, Kingston and Noonan (2014). One Dutch study identified considerable issues with social and occupational adjustment in about two-thirds of the participants (Hellendoorn and Ruijssenaars, 2000). However, there are also other studies showing that individuals with dyslexia exhibited patterns of functional and emotional compensation in adult life sometimes even demonstrating giftedness (McNulty, 2003). Most adults living with this condition reported that the encouragement of their talents supported their search for self-worth (Osmond, 1993).

\subsection{Dyslexia and visuospatial ability}

It has often been postulated that many persons with dyslexia are gifted with talents in various non-academic areas (Geschwind \& Galaburda, 1987). Persons with dyslexia are disproportionately represented in professions requiring spatial abilities and talents such as engineering, construction and mechanical work (Brunswick, Martin, \& Marzano, 2010; Symonds, 2005; Winner, Casey, DeSilva, \& Hayes, 1991; Winner et al., 2001; Wolff, 2011; Wolff \& Lundberg, 2002). According to several studies, some persons with dyslexia have innovative ways of thinking and are able to see things from a different perspective (e.g. Davis, 1997; West, 1997; West, 2008) and visualisation is probably their primary mode of thought. They tend to use techniques that rely on visual representation and reasoning (Bacon \& Handley, 2010). It seems that this preference for visual strategies is essential as a compensatory technique for overcoming memory issues that individuals with dyslexia often experience (Davis, 1997). This visual strategy, which is in effect a type of intelligence, is assuming increasingly importance with the rise of technology (Shea, Lubinski, \& Benbow, 2001) and spatial ability has been found to be a good predictor of success in various areas of modern life (Lubinski, 2010; Mohler, 2008). While good literacy based communication skills need to be encouraged, spatial giftedness will have increasing importance in the diverse demands for different skills that new technologies require (Shea et al., 2001; West, 2008).

There are various definitions of dyslexia. These include those by Lyon, Shaywitz, and Shaywitz (2003), the definition in the Rose Report (2009) and the definition in the ICD-10 International Statistical Classification of Diseases and Related Health Problems (2016). It is not the aim of this article to discuss these definitions; rather, it considers the possibility that dyslexia is a condition with associated non-language related attributes (Gilger, Allen, \& Castillo, 2016). The Rose Report (2009) definition is based on the theory that dyslexia is often accompanied by gifts in the visual-spatial arena, a view consistent with Geschwind and Galaburda's pathology of superiority theory (1987) and it considers a wider array of characteristics of individuals with dyslexia, including their increased design, problem-solving, creative, interactive and oral skills, than do the other definitions.

Studies that link dyslexia with higher visual-spatial abilities span three decades (Galaburda \& Kemper, 1979; Galaburda, Sherman, Rosen, Abolitiz, \& Geschwind, 1985; Rimland \& Fein, 1988; West, 1999; Wolf \& Lundberg, 2002). Geshwind and Galaburda (1987) observed that a large number of individuals with reading problems tended to be engaged in professions requiring well-developed spatial skills such as engineering and architecture. An article compiled from Geshwind's writings (Sherman and Cowen, 2010) also referred to possible advantages a person with dyslexia may possess; "the very same anomalies on the left side of the brain that have led to the disability of dyslexia in certain literate societies also determine superiority in the same brains" (p. 15). Consistent with this array of studies is the finding that there are disproportionately more persons with dyslexia in populations of artists than in the general population (Winner \& Casey, 1993; Winner et al., 1991) and several other studies demonstrate that individuals with dyslexia are disproportionately represented in occupations that require higher spatial skills (Brunswick, Martin, \& Marzano, 2010). Similarly, individuals with reading difficulties are more likely to become artists (Winner \& Casey, 1993) or mathematicians (Bloom, 1985) and there is a higher prevalence of dyslexia among art students attending tertiary education (Wolf \& Lundberg, 2002).

There are many attempts to explain the origins of language deficiencies in affected individuals. According to Galaburda \& Kemper (1979), individuals with dyslexia have atypical brains and their left hemisphere, which is responsible for verbal processing, is different (Riccio \& Hynd, 1996). Studies that use functional magnetic resonance imaging (fMRI) that measures the blood flow to functioning areas of the brain and positron emission tomography (PET) scans that measure the metabolic activity in brain tissue have revealed that individuals with dyslexia have a reduced activation of the left-brain region when compared with individuals without dyslexia (Sun, Lee, \& Kirby, 2010). Shaywitz and Shaywitz (1999) identified differences in the right hemisphere associated with non-linguistic tasks. In their study, when they presented individuals with dyslexia with visual-spatial activities, they displayed greater activation in the right hemisphere 
than unimpaired readers did. Similarly, other studies demonstrate that individuals with dyslexia are predisposed to use right hemispheric function even during reading tasks that normally generate greater left hemispheric activation (Grigorenko, 2001). Research also shows that individuals with dyslexia experience disruptions of the neuronal connections more frequently than average readers do. They also have a greater number of axons than average readers that survive the pruning process in the brain's development (Stein, 2001). This explains the enhanced spatial skills of those individuals with dyslexia who are reported in the literature to be gifted in this domain (Winner \& Casey, 1993; Winner et al., 1991; Brunswick et al, 2010).

\section{Assessment Issues and the Formulation of Visuospatial Ability in Tests}

Although the notion of the general intelligence factor (g) defined by Spearman (1927) continued to be supported until the turn of this century by no other than Jensen (1998), Mohler (2008) pins the first indication to the acknowledgment of more than one factor to Thorndike (1921). Subsequently, Kelley (1928), El Koussy (1935), and Thurstone (1938) all identified spatial ability as an intellectual construct separate from the general intelligence factor. Later on Guilford (1967) and Cattell (1971) provided alternative theories to the ' $g$ ' factor theory and Gardner's (1993) multiple intelligences theory additionally supported the position of spatial ability as an important dimension of the cognitive spectrum. Carroll's (1993) comprehensive study of visuospatial skills identified major factors including visualisation, spatial relations, closure speed, closure flexibility and perceptual speed, with the first two being the most robust factors. According to Lubinski (2010), spatial talent is a salient characteristic of young adolescents studying science, technology, engineering or mathematics (STEM) and is a good predictor of later educational achievement in STEM areas. Gardner (1993) also emphasizes that spatial ability determines students' progress in the sciences. Despite strong evidence that spatial ability is a good predictor of success in many areas of life (Lohman, 1994; Lubinski, 2010; Mohler, 2008) this important dimension of human ability is not fully recognised. Major international literacy policy initiatives such as the United Nations Literacy Decade: 2003-2012, UNESCO's Literacy Initiative for Empowerment (LIFE) and the European Commission's European Policy Network of National Literacy Organisations as well as the Literacy Strategy for All - 2014-2019 of the Maltese Ministry of Education and Employment emphasize the importance of acquiring basic proficiency in literacy, numeracy, and digital literacy; however, they rarely refer to spatial ability. Numerous studies (e.g. Shea et al., 2001; Geschwind \& Galaburda (1987) argue that education systems cannot afford to neglect this crucial feature of the "human cognitive repertoire" (Shea et al., 2001, p. 612). If one does so, then one ignores a small but significant pool of resources in our population, this apart from frustrated occupational goals and loss of potential careers.

\subsection{Researching visuospatial skills}

Currently, research into this area appears to be conducted using paper-and-pencil and computer-generated and even immersive virtual reality tests that create simulated experiences, which facilitate the assessment of visuospatial skills (Rizzo, Parsons, Kenny, \& Buckwalter, 2012).

\subsubsection{Paper-and-pencil tests}

Duranovic, Dedeic and Gavrić (2015) assessed whether students with dyslexia (symptomatic) exhibited superior visualisation strategies in comparison to average students (asymptomatic). In one such test, the Paper Folding Test (previously used by Ekstrom, French, Harman, \& Dermen, 1976), participants were required to predict how a piece of a paper would look, after it had been folded, punched with a hole and unfolded once again. Duranovic et al. (2015) identified higher analytical and mental visualisation techniques among students with dyslexia than average readers. Similar skills were identified by other researchers like Brunswick et al. (2010) in males with dyslexia who demonstrated superiority at reproducing designs and at recalling the direction of the Queen's head on a stamp. Winner, von Károlyi, \& Malinsky (2000) used the Form Board task to measure spatial visualisation that is, according to Carroll (1993) one of the major factors in the domain of visual perception. In this study, symptomatic participants were better able to select jigsaw pieces that made up the whole shape by mentally manipulating spatial patterns. When using a different technique to assess for spatial visualisation Winner et al. (2000) reported that participants with dyslexia performed better, but not statistically significantly so, than the control group in a visualisation task involving an experiment with Archimedes' screw. Conversely, when Winner et al. (2000) administered the Vandenberg Test of Mental Rotation to adolescents with dyslexia, they performed significantly worse than the comparison group in identifying the correctly rotated version of the 
target image. When Duranovic et al. (2015) used this same measure, no difference was evident in the ability of symptomatic students and average readers to perform mental rotation tasks. Winner et al. (2000) found no differences between participants with dyslexia and the control group on the copying task of the Rey-Osterrieth Complex Figure (ROCF). Furthermore, they recorded that symptomatic participants performed significantly worse when immediate recall was assessed. Likewise, Duranovic et al. (2015) found no effect of having dyslexia on the copying task of the ROCF except that symptomatic respondents were less successful in the immediate recall. Similarly, an earlier study (Lipowska, Czaplewska, \& Wysocka, 2011) found that children with dyslexia were less accurate and precise than skilled readers when copying the same ROCF figure. In this case, the work of the symptomatic group lacked elaboration and had several important elements missing. Rusiak, Lachmann, Jaskowski, \& van Leeuwen (2007) likewise noted that they identified no connection whatsoever between dyslexia and visuospatial processes in their part of the study involving geometric shapes.

\subsubsection{Computer-generated tests}

Research on computer-based visual-spatial ability is promising but the application of this technology is still limited. Von Károlyi (2001) used two computer-based visual-spatial tasks including the Impossible Figures and the Celtic Matching Task. The Impossible Figures Task is designed to assess global visuospatial discrimination; a right brain hemisphere process. Participants in her study were requested to identify impossible line drawings of three-dimensional objects by observing various features simultaneously. The experimental group was faster at identifying impossible figures than the average group. This study was replicated on another group of participants and this time too, individuals with dyslexia were able to recognize impossible figures significantly more rapidly, and no less accurately, than average participants (Von Károlyi, Winner, Gray, \& Sherman, 2003). The Celtic Matching Task, designed to assess local visual-spatial processing engages primarily the left hemisphere of the brain. Success on this task depends on the participants' ability to attend to the small detail in each figure and to identify which one is identical to the target form. Von Károlyi et al, (2003) reported that males with dyslexia were less successful on this task than average reading females who achieved the same scores as the other females of the comparison group. The males with dyslexia performed below the level of the average reading males. Overall, there were no significant differences between the four groups.

More recent studies such as that by Attree, Turner and Cowell (2009) reported that the application of computergenerated tests holds some advantages over conventional tests when measuring the visuospatial abilities of participants with dyslexia. In their study, participants were encouraged to explore a virtual bungalow presented on a computer screen using a keyboard and were later asked to recreate the layout from memory using two-dimensional cardboard shapes. When compared to average participants, teenagers with dyslexia exhibited better spatial orientation and an enhanced visualisation and reference memory on the virtual environment test. In comparison, Attree et al. (2009) found no statistically significant difference between the two groups on the conventional visuospatial tests they used, these being part of the British Ability Scales battery.

Wang and Yang (2011) created a virtual environment test to compare the visuospatial abilities of students with dyslexia and average students. They instructed ten to twelve-year-old participants to manipulate the objects presented on screen by pressing the mouse and rotating three-dimensional figures to find a hidden ball. Although they found no differences between the groups in the number of correct responses, they found a substantial difference in the speed of processing and distinguishing three-dimensional figures. Findings from this study support the view that participants with dyslexia have better visuospatial processing ability.

The literature shows that males tend to score higher than females on numerous tests of spatial ability (Brunswick et al., 2010; Mohler, 2008; Voyer, Voyer, \& Bryden, 1995) but others failed to find sex differences (Duranovic et al., 2015). In some studies, women are reported to be more variable on certain visuospatial tasks (Halpern, 1992; Kimura, 1996). In others like Object-Location Memory, Voyer, Postma, Brake and Imperato-McGinley (2007) suggest that females usually possess a degree of advantage.

\section{Aims}

In the tradition of quantitative research, the study is based on the following hypotheses: There is no significant difference in the visuospatial abilities of adolescents with dyslexia (symptomatic) and average adolescents (asymptomatic) when assessed through a paper-and-pencil test medium $\left(\mathrm{H}_{0} 1\right)$. There is no significant difference in the visuospatial abilities of symptomatic and asymptomatic readers when assessed through a virtual environment test medium $\left(\mathrm{H}_{0} 2\right)$. Additionally, 
there is no significant difference in the visuospatial abilities of males and females on any of the measures administered in this study $\left(\mathrm{H}_{0} 3\right)$. The study was approved by the institutional research ethics committee and the school administrators.

\section{Method}

\subsection{Participants}

Participants came from three different regional colleges in Malta, purposely selected to cover the northern, the central and the southern localities of the island to ensure adequate representation. In this study, a group of 38 mixed-gender adolescents with dyslexia aged between 12 and 14 years was compared with a matched group of students on aspects of visuospatial ability. All 38 participants with dyslexia, according to their educational needs documentation (statementing) possessed average intelligence quotients. The members of the comparison group were selected from average groups for English language classes. Pairing was conducted on the basis of age, gender and socio-economic background. In total, the sample included 44 males and 32 females. Since dyslexia is much more prevalent in males than in females (Hawke, Olson, Willcutt, Wadsworth, \& Defries, 2009; Rutter et al., 2004) this was also reflected in the sample, albeit unintentionally so.

\subsection{Assessment instruments}

Three assessment instruments were used in this study and these constituted one reading comprehension test and two tests of visuospatial ability. The Suffolk English Reading Comprehension Test Level 2 (Hagley, 2002) with Maltese norms (University of Malta/Access Disability Support Committee \& Ministry of Education / Directorate for Quality and Standards in Education, 2010) was used to confirm the literacy status of the two groups. This ensured that they were indeed a group of participants with literacy difficulties and a comparison group with no literacy difficulties.

In line with the above review of studies on paper-and-pencil and virtual environment tests, the authors used one test of each type to explore the hypotheses posited in this study. All participants completed the Spatial Reasoning test (Smith \& Lord, 2002a) which is a paper-and-pencil group administered test and the Virtual Bungalow test that was administered individually. This test was an emulation of the original test used by Attree et al. $(1996,2009)$ and Brooks, Attree, Rose, Clifford, and Leadbetter (1999). It was commissioned for this study using Unity software, a cross-platform game engine. Instructions were in both Maltese and English. Testing of all the participants was done during school hours within a three-week period. Both tests were administered to each participant on the same day during two separate lessons.

\subsubsection{Paper-and-pencil visuospatial assessment}

The Spatial Reasoning Test (Smith \& Lord, 2002b), paper-and-pencil test battery includes visuospatial ability multiplechoice tests normed on the ages 12 to 14 years. It measures an aspect of visuospatial ability independently of language. The test consisted of 92 items divided into five subtests:

a. Hidden Shapes (ability to identify a hidden polygon),

b. Sections (the ability to visualise a three-dimensional object from a two-dimensional drawing);

c. Jigsaws (ability to mentally put together different jigsaw pieces and decide which of the four shapes make the finished design);

d. Wallpaper (ability to visualise the continuation of a two-dimensional pattern that is hidden from view) and

e. Right angles (ability to visualise a right angle despite the presence of conflicting visual information).

\subsubsection{Virtual reality visuospatial assessment (bungalow test)}

Before formal testing, participants completed a short simulation to become familiar with the virtual setting and the navigation procedure. On average, the exploration of the virtual bungalow took 5 minutes. Once navigation was ready, participants were requested to sit away from the computer and were given a set of 37 picture cards containing images of all the household items in the bungalow including 16 distractors. Distractors were included to limit any possible inflation of scores through guesswork. Students were requested to select the images they remembered seeing inside the virtual bungalow (21 household items and 16 distractors). The participants' object memory was scored out of a possible 21 
points; distractors selected by each participant were also recorded and a total score was generated by deducting a mark for each incorrect item. This picture recognition test assessed immediate recall of object memory and although not directly linked to visuospatial ability, it was an essential precursor to another activity that tested visuospatial memory. After five minutes, the researcher collected the selected cards and instructed participants to reconstruct the spatial layout of the virtual setting. This consisted of constructing a plan of the house using two dimensional cardboard shapes that had been drafted in proportion to the actual dimensions of each room. Thus, incidental memory for the spatial layout was tested for by analysing how participants perceived and remembered the virtual environment and its spatial orientation. Performance on this task was scored as spatial memory. Once this plan was constructed, the authors photographed the constructed layout and object placements to score and compare the results of both groups. Finally, participants were given an $\mathrm{A} 3$ sheet of paper depicting the correct layout of the virtual bungalow and asked to indicate the exact location of the objects used earlier. One object indicative of the function of each room was left purposely to help participants identify the particular rooms; a bed was placed in the bedroom, a piano in the music room, a sofa in the sitting room and a sink in the kitchen. Pictures of the objects which were earlier identified as being present in the virtual house were handed once again to the participants and their task was to write down the corresponding number of each picture onto the plan in order to show the exact location where each object was placed. The aim of this task was to assess object-location memory. The scoring for this object-location memory test was adopted from Brooks et al. (1999) who allocated two marks for the correct location of each object recalled; one mark for the correct room and another mark for the correct location within the room. The correct location was determined by dividing each room into six equal sectors and requiring that each object be located in its appropriate position. This virtual environment test fulfilled the necessary requirements of a virtual setting since a virtual test should enable participants to interact and move freely around the virtual environment without the possibility of passing through the virtual objects to make it more realistic (Durlach \& Mavor, 1995).

\section{Analysis and Results}

In order to examine differences between groups, the authors conducted various analytical procedures using the IBM SPSS Statistics Version 23. Normality of distribution of scores was established by the Shapiro-Wilk test along with a visual inspection of the results. The Independent-Samples t-test (parametric) for significant differences between groups was conducted for scores that were normally distributed and the Mann-Whitney $U$ test was employed when this assumption of normality was not upheld.

The mean standard scores for reading ability are reported in Table 1. Skilled readers outperformed the participants with dyslexia on the English reading comprehension test. The difference between the two groups was statistically significant, $t(64.821)=-11.545, p=<.001$. Hence, these scores validated the sample and confirmed that the two groups consisted of poor and average readers.

Table 1. Participants' sex, age and literacy scores

\begin{tabular}{lcc}
\hline & Students with dyslexia Asymptomatic students \\
\hline Males & $\mathrm{N}=22$ & $\mathrm{~N}=22$ \\
\hline Females & $\mathrm{N}=16$ & $\mathrm{~N}=16$ \\
\hline Total & $\mathrm{N}=38$ & $\mathrm{~N}=38$ \\
\hline Age of participants, mean months and (SD) & $160(10.1)$ & $160(9.6)$ \\
\hline Mean score in Suffolk Reading Scale (SD) & $79.1(8.67)$ & $99.08(5.98)$ \\
\hline
\end{tabular}

Before analysing differences between groups, the data was evaluated to assess whether the test scores were normally distributed. Normality was assessed statistically and visually according to procedures suggested by Maxwell and Delaney (2004). The Shapiro-Wilk test, the best test of normality (Myers, Well, \& Lorch, 2010) established the score distribution of the two visuospatial tests. As Table 2 shows, the Shapiro-Wilk test revealed that the score distribution of Hidden Shapes and the total standard score of the Spatial Reasoning test were normal but the score distributions of the other four subtests (Sections, Jigsaws, Wallpaper and Right Angles) had a non-normal distribution with $p$-values less than the 0.05 criterion. These assumptions were further supported by a visual inspection of the normal $Q-Q$ plot of each test. 
Table 2. Results of Shapiro-Wilk test for the Spatial Reasoning test

\begin{tabular}{llll}
\hline Shapiro-Wilk & & & \\
\hline & W Statistic & d.f. & P-Value \\
\hline Hidden Shapes & .98 & 76 & .27 \\
\hline Sections & .95 & 76 & .01 \\
\hline Jigsaws & .97 & 76 & .04 \\
\hline Wallpaper & .97 & 76 & .04 \\
\hline Right Angles & .97 & 76 & .04 \\
\hline Total Standard Score & .99 & 76 & .65 \\
\hline
\end{tabular}

Four measures were compiled for the Virtual Bungalow test (Object Memory, Object-Location Memory, Total Spatial Memory and Total Bungalow Score) of which only the scores for the Object-Location Memory were normally distributed (Table 3) and these results were consistent with a visual examination of the normal $Q-Q$ plots for the four measures.

Table 3. Results of Shapiro-Wilk for the Virtual Bungalow test.

\begin{tabular}{lccc}
\hline Shapiro-Wilk & & & \\
\hline & W Statistic & df & P-Value \\
\hline Object Memory & .89 & 76 & $<.001$ \\
\hline Spatial Memory Test & .91 & 76 & $<.001$ \\
\hline Object-Location Memory & .97 & 76 & .09 \\
\hline Total Bungalow Score & .97 & 76 & .033 \\
\hline
\end{tabular}

In all cases, where means of normally and non-normally distributed scores were analysed for statistically significant differences, the appropriate parametric and nonparametric tests were applied.

\subsection{Paper-and-pencil visuospatial assessment (Spatial Reasoning Test) null hypothesis $1\left(\mathrm{H}_{0} 1\right)$}

Comparisons of the computed standardised means obtained by both groups on each subtest show that the asymptomatic group outperformed the symptomatic group in three of the five subtests in this battery of tests. The asymptomatic group obtained a higher average score on Hidden Shapes, Jigsaws, and Right Angles. On the contrary, the symptomatic group obtained a slightly higher average score on Sections and Wallpaper. The computed mean standardised score for all five subtests is $101(S D=9.9)$ for the research group and $98.9(S D=10.6)$ for the comparison (asymptomatic) group is presented in Table 4.

Table 4: Mean scores, t-test and Mann-Whitney test for the Spatial Reasoning Test by group.

\begin{tabular}{|c|c|c|c|c|c|c|c|}
\hline Group & Hidden Sha & Section & igsaw & Vallpap & ght Ang & andar & \\
\hline Symptomatic & Mean & 97.3 & 101 & 99.3 & 100 & 96.6 & 98.9 \\
\hline $\mathrm{n}=38$ & SD & 16.6 & 14.3 & 15.9 & 15.1 & 14.0 & 10.6 \\
\hline Asymptomatic & Mean & 98.5 & 99.2 & 101 & 99.8 & 103 & 101 \\
\hline$n=38$ & SD & 12.9 & 15.8 & 14.3 & 15.1 & 15.3 & 9.9 \\
\hline Independent-samples t-test & & $\begin{array}{l}t(74)= \\
-1.61, \mathrm{r}\end{array}$ & & & & & $\begin{array}{c}t(74)= \\
-.972, \mathrm{~ns}\end{array}$ \\
\hline
\end{tabular}

There were no significant differences between the scores of the symptomatic and the asymptomatic groups on any of the subtests. Analysis revealed that adolescents with dyslexia had similar overall performance as the participants without dyslexia in all the five subtests. Therefore, the null hypothesis $\left(\mathrm{H}_{0} 1\right)$ was retained. This concludes that in this sample of 12 to 14-year old students, there were no statistically significant differences in the visuospatial abilities of symptomatic and asymptomatic groups when assessed through a paper-and-pencil test.

\subsection{Virtual reality visuospatial assessment (Bungalow Test) null hypothesis $2\left(\mathrm{H}_{0} 2\right)$}

Null hypothesis 2 postulated that there is no difference in the visuospatial abilities of symptomatic and asymptomatic 
adolescents using a virtual environment measure, the Bungalow test. This test consisted of three different measures: Object Memory, Spatial Memory, and Object-Location Memory. The computed mean standardised scores, presented in Table 5, show that the asymptomatic group scored better than the symptomatic group on the Object Memory test, the Object-Location Memory test and the Total Bungalow score. The symptomatic group performed better than the asymptomatic group on the Spatial Memory test.

Table 5: Mean scores, t-test and Mann-Whitney test for the Bungalow Test by group.

\begin{tabular}{|c|c|c|c|c|}
\hline Group & \multicolumn{4}{|c|}{ Object Memory test Spatial Memory test Object-Location Memory test Total Bungalow score } \\
\hline Mean & 97.3 & 101.1 & 99.4 & 99.3 \\
\hline Symptomatic participants $n=3$ & 17.6 & 13.5 & 14.8 & 12.3 \\
\hline Asymptomatic participants & 103 & 98.9 & 101 & 101 \\
\hline$n=38$ & 11.4 & 16.4 & 15.4 & 11.8 \\
\hline Independent-samples t-test & & & $=-.37$ & \\
\hline Mann-Whitney U test & $630, \mathrm{~ns}$ & $690, \mathrm{~ns}$ & & $677, \mathrm{~ns}$ \\
\hline
\end{tabular}

There were no significant differences between the scores of the symptomatic and the asymptomatic groups on any of the subtests. Analyses revealed that adolescents with dyslexia had similar overall performance as the participants without dyslexia in all four measures. Therefore, the null hypothesis $\left(\mathrm{H}_{0} 2\right)$ was retained. This concludes that in this sample of 12 to 14-year-old students, there were no statistically significant differences in the performance of symptomatic and asymptomatic adolescents on the Bungalow Test.

These results do not lend support to some recent studies (Attree et al., 2009; Wang and Yang, 2011) that advocate the use of virtual environment tests as a better option than paper-and-pencil tests as more sensitive in the assessment of students' visuospatial abilities. On the other hand, in this study, there may have been no differences to explore, as the two groups did not differ in their visuospatial skills.

\subsection{Sex differences null hypothesis $3\left(\mathrm{H}_{0} 3\right)$}

In all the tests reported in this study, males performed better than females as shown in tables 6 and 7 .

Table 6: Mean scores, t-test and Mann-Whitney test for the Spatial Reasoning Test by sex.

\begin{tabular}{lccccccc}
\hline Sex & \multicolumn{7}{c}{ Hidden Shapes Sections Jigsaws Wallpaper Right Angles Total Standard score } \\
\hline Males & Mean & 101 & 102 & 102 & 102 & 102 & 100 \\
\cline { 2 - 9 } $\mathrm{n}=44$ & $\mathrm{SD}$ & 13.7 & 15.0 & 15.5 & 15.2 & 16.1 & 9.3 \\
\hline Females & Mean & 98.7 & 97.7 & 97.5 & 97.9 & 97.5 & 97.0 \\
\cline { 2 - 8 } $\mathrm{n}=32$ & $\mathrm{SD}$ & 16.7 & 14.9 & 14.1 & 13.1 & 13.1 & 12.3 \\
\hline Independent-samples t-test & $t(74)=.601, \mathrm{~ns}$ & \multicolumn{7}{c}{$599, \mathrm{~ns}$} & $605, \mathrm{~ns}$ & $604, \mathrm{~ns}$ & $604, \mathrm{~ns}$ & $t(74)=.922, \mathrm{~ns}$ \\
\hline Mann-Whitney U test & \multicolumn{7}{c}{}
\end{tabular}

Table 7: Mean scores, t-test and Mann-Whitney test for the Bungalow Test by sex.

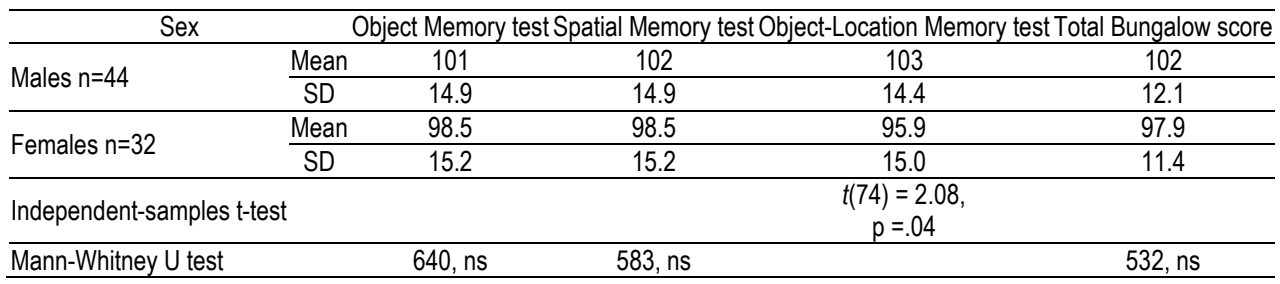

This result lends support to earlier studies such as those by Brunswick et al. (2010), Mohler (2008) and Voyer et al. (1995). An independent-samples t-test indicated that for Object-Location Memory, the score of the male group ( $M=103$, $S D=14.4$ ) was significantly higher than the scores of the female group $(M=95.9, S D=15), t(74)=2.08, p=.04)$. This was the only case out of 8 subtests where the null hypothesis was rejected and where males were in a clear advantage over females. Therefore, while some advantage in the measures of visuospatial awareness administered in this study may be attributed to boys, this is by no means universally statistically significant. 


\section{Discussion and Conclusion}

Although there is much interest in the visuospatial abilities of individuals with dyslexia as demonstrated by the studies outlined above, it is difficult to provide a definite answer to the question whether young people with dyslexia do possess enhanced visuospatial skills. Findings vary considerably. In the light of the obtained results, some appeared to magnify the spatial talent of individuals with dyslexia (Brunswick et al., 2010; Geschwind \& Galaburda, 1987; Gilger et al., 2016; Symonds, 2005; Winner et al., 1991, Winner et al., 2001; Wolff, 2011; Wolff \& Lundberg, 2002). On the other hand, other studies failed to find consistent significant differences between individuals affected with dyslexia and the average participant (Brunswick et al., 2010; Duranovic et al., 2015; Rusiak et al., 2007; Wang and Yang, 2011; Winner et al., 2000). These inconsistencies may be the result of differences in data collection, different age groups or the gender of participants, as well as the degree and severity of the dyslexic type difficulties experienced by participants. Such diverse findings indicate the need for additional investigations. Neither can it be said on the basis of the results of this study that males enjoy any advantage in completing spatial skill tasks over females.

Whilst it may be argued from an academic standpoint that a visuospatial advantage may only be evident through the employment of a narrow range of tests, it renders this advantage, if one does exist, specific to particular spatial tasks and one that can only be expressed in a strictly controlled situation or environment. In all the subtests administered for this study (Spatial Reasoning Test and the Bungalow Test) there was no clear advantage of the group of symptomatic individuals over the group of asymptomatic individuals. The only significant finding was one of general male superiority on all the subtests but with the difference between the two groups (male/female) reaching significant levels in just one instance, on the Object-Location Memory task that was a component of the virtual environment Bungalow Test.

Gender differences in spatial awareness are usually not significant in children younger than 13 years of age but differences start becoming significant in adolescents and adults (Voyer et al., 1995). However, in the present study, differences were consistently evident in children younger than 13 years even if only statistically significantly so in one measure. This lends support to findings by Brunswick et al. (2010), Mohler (2008), Voyer et al. (1995) and Winner et al. (2000) whose research found that males perform better than females on visuospatial tests. What seems to be anomalous is that the only one significant instance of male superiority (Object-Location Memory) is a skill that Voyer et al. (2007) suggest is usually, but not exclusively associated with female superiority.

The results from this study suggest that spatial ability is an extensive cognitive factor that it is often difficult to identify, measure and compare (Carroll, 1993). Furthermore, research on dyslexia and visuospatial ability is ongoing and knowledge about this condition is partial. The findings from this study have some practical implications that are useful for teachers in particular. Certainly, teachers should not expect young children and adolescents with dyslexia to possess any particular spatial skills that could in any way been deemed to compensate for their literacy difficulties. Neither should they assume that any superior spatial awareness is to be expressed in school-based subjects that are not language-based. Rather these children should be supported in their learning difficulties like other children with other needs. It should not be assumed that there are significant differences between male and female students in their ability to deal with spatial tasks; girls are effectively as able as boys are in most situations.

More research is required before one can settle the issue of any palpably significant differences between adolescents with dyslexia and their peers who are average readers. In terms of possible sex differences, the jury is clearly still out. Additionally, the area is replete with variations in test measures and procedures that are likely to have an effect on the results obtained, this apart from the usually small numbers of participants who are available for such studies with deleterious effects on the strength of the associations explored. One hopes that the present findings shed some small light on this interesting area of inquiry.

\section{References}

Attree, E. A., Brooks, B., Rose, F., Andrews, T., Leadbetter, A., \& Clifford, B. (1996). Memory processes and virtual environments: I can't remember what was there, but I can remember how I got there. Implications for people with disabilities. In Proceedings of the ECDVRAT: 1st European Conference on Disability, Virtual Reality and Associated Technologies, 117-121.

Attree, E., Turner, M. J., \& Cowell, N. (2009). A virtual reality test identifies the visuospatial strengths of adolescents with dyslexia. CyberPsychology and Behaviour, 12(2), 163-168.

Bacon, A. M., \& Handley, S. J. (2010). Dyslexia and reasoning: The importance of visual processes. British Journal of Psychology, 101, 433-452.

Barbiero, C., Lonciari, I., Montico, M., Monasta. L., Penge, R., Vio. C., Tressoldi, P. E., Ferluga, V., Bigoni, A., Tullio, A., Carrozzi, M., \& Ronfani, L. (2012). The Submerged Dyslexia Iceberg: How many school children are not diagnosed? Results from an Italian Study. PLOS ONE 7(10), 1-9. doi:10.1371/journal.pone.0048082 
Beddington J, Cooper C.L, Field J, Goswami, U., Huppert F.A., Jenkins R, Jones, H.S., Kirkwood T.B., Sahakian B.J., \&Thomas, S.M. (2008). Nature, 455, 1057-60. doi: 10.1038/4551057a

Bloom, B. (1985). Developing talent in young people. New York: Ballantine.

Brooks, B., Attree, E., Rose, D., Clifford, B., \& Leadbetter, A. (1999). The specificity of memory enhancement during interaction with a virtual environment. Memory, 7(1), 65-78.

Brunswick, N., Martin, G. N., \& Marzano, L. (2010). Visuospatial superiority in developmental dyslexia: myth or reality? Learning and Individual Differences, 20(5), 421-426.

Carroll, J. B. (1993). Human Cognitive Abilities: A survey of factor-analytic studies. Australia: Cambridge University Press.

Cattell, R. B. (1971). Abilities: Their structure, growth and action. Boston: Houghton-Mifflin.

Davis, R. D. (1997). The Gift of Dyslexia. London: Souvenir Press.

Duranovic, M., Dedeic, M., \& Gavrić, M. (2015). Dyslexia and Visual-Spatial Talents. Current Psychology, 34(2), 207-222.

Durlach, N. I., \& Mavor, A. S. (Eds.). (1995). Virtual Reality: Scientific and technical challenges. Washington DC: National Academy Press.

Ekstrom, R. B., French, J. W., Harman, H. H., \& Dermen, D. (1976). Kit of factor referenced cognitive tests. Princeton: Educational Testing Service.

El Koussy, A. A. H. (1935). The visual perception of space. British Journal of Psychology, 20, 1-80.

Elbaum, B., \& Vaughn, S. (2001). School-based interventions to enhance the self-concept of students with learning disabilities: A metaanalysis. The elementary school journal, 101(3), 303-329.

Galaburda, A. M., \& Kemper, T. L. (1979). Cytoarchitectonic organization of the human auditory cortex. Journal of Comparative Neurology, 190, 597-610.

Galaburda, A. M., Sherman, G. F., Rosen, G. D., Aboitiz, F., \& Geschwind, N. (1985). Developmental Dyslexia: Four Consecutive Patients with Cortical Anomalies. Annals of Neurology, 18, 222-233.

Gardner, H. (1993). Frames of Mind: The Theory of Multiple Intelligences. New York: Basic Books.

Gerber, P. (2012). The impact of learning disabilities on adulthood: A review of the evidenced-based literature for research and practice in adult education. Journal of Learning Disabilities, 45(1), 31-46.

Geshwind, N., \& Galaburda, A. (1987). Cerebral lateralization. Cambridge: MIT Press.

Gilger, J.W., Allen, K., \& Castillo, A. (2016). Reading disability and enhanced dynamic spatial reasoning: A review of the literature. Brain and Cognition, 105, 55-65. doi: 10.1016/j.bandc.2016.03.005.

Grigorenko, E. L. (2001). Developmental dyslexia: An update on genes, brains and environment. Journal of Child Psychology and Psychiatry, 42, 91-125.

Guilford, J. P. (1967). The nature of human intelligence. New York: McGraw-Hill.

Hagley, F. (2002). Suffolk Reading Scale 2: Version 2. London: Nfer-Nelson.

Halpern, D. F. (1992). Sex differences in cognitive abilities (2nd ed.). New Jersey: Lawrence Erlbaum Associates.

Hawke, J. L., Olson, R., Willcutt, E. G., Wadsworth, S., \& DeFries, J. C. (2009). Gender ratios for reading difficulties. Dyslexia, 15(3), $239-242$.

Hellendoorn, J., \& Ruijssenaars, W. (2000). Personal experiences and adjustment of Dutch adults with dyslexia. Remedial and Special Education, 21, 227-239.

Jensen, A. R. (1998). The g-factor, the science of mental ability. Westport, CT.: Praeger.

Kelley, T. L. (1928). Crossroads in the mind of man. Stanford, CA.: Stanford University Press.

Kimura, D. (1996). Sex, sexual orientation and sex hormones influence human cognitive function. Current Opinion in Neurobiology, 6(2), 259-263.

Lipowska, M., Czaplewska, E., \& Wysocka, A. (2011). Visuospatial deficits of dyslexic children. Medical Science Monitor, 17(4), $216-221$.

Lohman, D. F. (1994). Spatially gifted, verbally inconvenienced. In N. Colangelo, S. G. Assouline, \& D. L. Ambroson (Eds.), Talent development: Vol 2. Proceedings from the 1993 Henry B. and Jocelyn Wallace National Research Symposium on Talent Development (pp. 251-264). Dayton: Ohio Psychology Press.

Lubinski, D. (2010). Spatial ability and STEM: A sleeping giant for talent identification and development. Personality and Individual Differences, 49, 344-351.

Lyon, G. R., Shaywitz, S. E., \& Shaywitz, B. A. (2003). A definition for Dyslexia. Annals of Dyslexia, 53, 1-14. doi:10.1007/s11881-003$0001-9$.

Lyon, R. G. (2003). Defining dyslexia, comorbidity, teachers' knowledge of language and reading. Annals of Dyslexia, 53, 1-14.

Maxwell, S. E., \& Delaney, H. D. (2004). Designing experiments and analyzing data: A model comparison perspective (2nd ed.). New York: Psychology Press.

McNulty, M. (2003). Dyslexia and the Life Course. Journal of Learning Disabilities, 363-381.

Ministry of Education and Employment. (2012). A National Curriculum Framework for All. Malta: Salesian Press.

Mohler, J. L. (2008). A review of spatial ability research. Engineering Design Graphics Journal, 19-30.

Myers, J. L., Well, A. D., \& Lorch, R. F. (2010). Research design and statistical analysis (3rd ed.). New York: Routledge.

Osmond, J. (1993). The Reality of Dyslexia. London: Wellington.

Peterson R.L., \& Pennington, B.F. (2012). Developmental dyslexia. Lancet, 379, 1997-2007. doi: 10.1016/S0140-6736(12)60198-6. Epub 2012 Apr 17

Riccio, C. A., \& Hynd, G. W. (1996). Neuroanatomical and neurophysiological aspects of dyslexia. Topics in language disorders, 16(2), 
$1-13$.

Rimland B., \& Fein, D. (1988). Special talents and autistic savants. In: L.K. Obler, \& D. Fein, (Eds.). The exceptional brain: neuropsychology of talent and special abilities (pp. 374-492). New York, NY.: Guilford Press.

Rizzo, A.A., Parsons, T.D., Kenny, P., \& Buckwalter, J.G. (2012). Using Virtual Reality for Clinical Assessment and Intervention. In L. L'Abate, \& D. Palmer. (Eds.) Handbook of Technology in Psychology, Psychiatry, and Neurology: Theory, Research, and Practice. Nova Science Publishers, (pp. 277-318), NY.: Hauppauge

Rose, J. (2009). Identifying and teaching children and young people with dyslexia and literacy difficulties. Retrieved from: https://www.education.gov.uk/publications/eOrdering Download/00659-2009DOM-EN.pdf

Rusiak, P., Lachmann, T., Jaskowski, P., \& van Leeuwen, C. (2007). Mental rotation of letters and shapes in developmental dyslexia. Perception, 36, 617-631.

Rutter, M., Caspi, A., Fergusson, D., Horwood, L., Goodman, R., Maughan, B., Moffitt, T.E., Meltzer, H., \& Carroll, J. (2004). Gender differences in reading difficulties: Findings from four epidemiology studies. Journal of the American Medical Association, 291, 118.

Scott, R. (2004). Dyslexia and Counselling. London: Whurr.

Shaywitz, S. E., \& Shaywitz, B. A. (1999). Cognitive and neurobiological differences in reading and in dyslexia. Developmental Neuropsychology, 16, 383-384.

Shea, D. L., Lubinski, D., \& Benbow, C. P. (2001). Importance of assessing spatial ability in intellectually talented young adolescents: A 20-year longitudinal study. Journal of Educational Psychology, 93(3), 604-614.

Sherman, G. F., \& Cowen, C. D. (2010). Norman Geschwind: A Man Out of Time. Perspectives on Language and Literacy, 36(1), 1417.

Siegel, L. (2006). Perspectives on dyslexia. Paediatrics and Child Health, 11(9), 581-587.

Smith, P., \& Lord, T. (2002a). Spatial Reasoning Test 12-14. London: GL Assessment.

Smith, P., \& Lord, T. (2002b). Spatial Reasoning (Age: 12-14) Teacher's Guide. London: GL Assessment.

Spearman, C. (1927). The abilities of man. London: Macmillan.

Stein, J. (2001). The magnocellular theory of developmental dyslexia. Dyslexia 7, 12-36. DOI: 10.1002:dys.186

Sun, Y. F., Lee, J. S., \& Kirby, R. (2010). Brain Imaging Findings in Dyslexia. Pediatr Neonatol, 51(2), 89-96.

Symonds, H. (2005). Designing effective curriculum for dyslexic students within art and design in higher education. London: London College of Communication, University of the Arts.

Thorndike, E. L. (1921). On the organization of the intellect. Psychological Review, 28, 141-151.

Thurstone, L. L. (1938). Primary mental abilities. Psychometric Monographs, No. 1.

Unity Technologies ApS. (2015). Unity 5.2.0. Retrieved from https:/unity3d.com/get-unity/download/archive?_ga=1.119541000. 1642573073.1478428817

University of Malta/Access Disability Support Committee \& Ministry of Education/Directorate for Quality and Standards in Education. (2010). Reading Comprehension and Spelling Tests in Maltese and English.

Vidyasagar, T., \& Pammer, K. (2009). Dyslexia: a deficit in visuo-spatial attention, not in phonological processing. Trends in Cognitive Sciences, 14(2), 57-63.

Von Károlyi, C. (2001). Visual-Spatial Strength in Dyslexia: Rapid discrimination of impossible figures. Journal of Learning Disabilities, $34(4), 380$.

Von Károlyi, C., Winner, E., Gray, W., \& Sherman, G. (2003). Dyslexia linked to talent: global visual-spatial ability. Brain and Language, 85(3), 427-431.

Voyer, D., Postma, A., Brake, B., \& Imperato-McGinley, J. (2007). Psychonomic Bulletin and Review 14(1), 23-38. doi:10.3758/BF03194024

Voyer, D., Voyer, S., \& Bryden, M. P. (1995). Magnitude of sex differences in spatial abilities: A meta-analysis and consideration of critical variables. Psychological Bulletin, 117, 250-270.

Wang, L., \& Yang, H. M. (2011). The comparison of the visuo-spatial abilities of dyslexic and normal students in Taiwan and Hong Kong. Research in Developmental Disabilities, 32, 1052-1057.

West, T. (1997). In the Mind's Eye (2nd ed.). New York: Prometheus Books.

West, T. (1999). The abilities of those with reading disabilities: focusing on the talents of people with dyslexia. In D.D. Duane (Ed.), Reading and attention disorders - neurobiological correlates (pp. 213-141). Baltimore: York Press.

West, T. (2008). It is time to get serious about the talents of dyslexics. Perspectives on Language and Literacy, 34(3), 9-11.

Winner, E., \& Casey, M. B. (1993). Cognitive profiles of artists. In G. C. Cupchik, \& L. J. Laszlo (Eds.), Emerging visions of the aesthetic process: Psychology, semiology, and philosophy (pp. 154-170). New York: Cambridge University Press.

Winner, E., Casey, M., DeSilva, D., \& Hayes, R. (1991). Spatial abilities and reading deficits in visual art students. Empirical Studies of the Arts, 9(1), 51-63.

Winner, E., von Károlyi, C., \& Malinsky, D. (2000). Dyslexia and visual-spatial talents: No clear link. Boston College Perspectives.

Winner, E., von Karolyi, C., Malinsky, D., French, L., Seliger, C., Ross, E., \& Weber, C. (2001). Dyslexia and visual-spatial talents: Compensation vs deficit model. Brain and Language, 76(2), 81-110.

Wolff, U. (2011). Artistic talents and dyslexia: A genuine connection? In N. Alexander-Passe (Ed.), Dyslexia and creativity: Investigations from differing perspectives (pp. 65-77). New York: Nova Science Publishers.

Wolf, U., \& Lundberg, I. (2002). The prevalence of dyslexia among art students. Dyslexia, 8, 34-42. 
World Health Organisation. (2016, March 8). International Statistical Classification of Diseases and Related Health Problems (ICD-10 Version). Retrieved from http://apps.who.int/classifications/icd10/browse/2016/en

Zheng, C., Gaumer Erickson, A., Kingston, N., \& Noonan, P. M. (2014). The relationships among self-determination, self-concept, and academic achievement for students with learning disabilities. Journal of Learning Disabilities, 47, 462-474. doi:10.1177/ 00222219412469688 